\title{
New, Simple and Validated RP-HPLC Method for Quality Control of Moxifloxacin
}

\author{
Safwan Ashour* and Nuha Kattan \\ Department of Chemistry, Faculty of Sciences, University of Aleppo, Aleppo, Syria
}

\begin{abstract}
Received: September 8, 2016; Accepted: September 27, 2016; Published: October 31, 2016
*Corresponding author: Safwan Ashour, Professor, Department of Chemistry, Faculty of Sciences, University of Aleppo, Aleppo, Syria, E-mail: profashour@ hotmail.com
\end{abstract}

\begin{abstract}
Simple, rapid, sensitive and accurate method for determination of moxifloxacin HCl (MOXF) in bulk drug and tablet formulation was developed and validated by using HPLC. Rosuvastatin calcium (ROSV) was used as internal standard. Chromatography was performed with mobile phase consisted of $0.1 \mathrm{M}$ formic acid (pH 2.80) and methanol $(30: 70, v / v)$, with a flow rate of $1.0 \mathrm{~mL} / \mathrm{min}$, Nucleodur $\mathrm{C} 18$ column ( $250 \mathrm{~mm} \times 4.6 \mathrm{~mm}$ i.d., $5 \mathrm{~m}$ particle size) and photodiode array (PDA) detection at $280 \mathrm{~nm}$. The method was validated for linearity, specificity, accuracy, precision, stability and robustness. Linearity range was $1.12-590.0 \mu \mathrm{g} / \mathrm{mL}$ with limit of detection value of 0.23 $\mu \mathrm{g} / \mathrm{mL}$. The precision of the method was demonstrated using intraand inter-day assay RSD $\%$ values which were less than $2 \%$, while the recovery was $99.11-103.85 \%$. The developed method was very rapid with a run time of $3 \mathrm{~min}$ and found to be successively applied for the quality control of MOXF in bulk drug and tablets.
\end{abstract}

Keywords: RP-HPLC; Moxifloxacin hydrochloride; Analysis; Validation

\section{Introduction}

Moxifloxacin (Figure 1), 1-cyclopropyl-6-fluoro-1,4dihydro-8-methoxy-7- $[(4 a S, 7 a S)$-octahydro- $6 \mathrm{H}-$ pyrrolo [3,4-b] pyridin-6-yl] 4-oxo-3-quinoline carboxylic acid [1] is a new fourth generation 8-methoxy fluoroquinolone antibacterial agent with a broad spectrum and improved activity against gram-positive bacteria (including staphylococci, streptococci, enterococci), anaerobes and atypical bacteria [2]. Various methods have been reported for the analysis of moxifloxacin in pharmaceutical dosage forms by flow injection with chemiluminescence detection [3], atomic absorption spectrometry [4], atomic absorption spectroscopy, conductometry and colorimetry [5], spectrophotometry [4,610], kinetics spectrophotometry [4, 11-13], voltammetry [14, 15], differential pulse polarography [16], spectrofluorimetry [17-19] and capillary electrophoresis [20,21]. Chromatographic methods such as reversed-phase HPLC/fluorescence [22-24], HPLC with ultra violet detection [25-27] and high-performance thin-layer chromatography [28] have been reported for the estimation of moxifloxacin hydrochloride in pharmaceutical products. Voltammetry [14, 15], spectrofluorimetry [17], high- performance liquid chromatography with fluorescence $[29,30]$ or UV detection [31-35], liquid chromatography tandem mass spectrometry (LC/MS/MS) [36, 37] and capillary electrophoresis $[38,39]$ are also reported for determination of moxifloxacin hydrochloride from human body fluids. British Pharmacopoeia (BP) [40] employs HPLC method for the assay of moxifloxacin hydrochloride in pharmaceutical preparations. Further, the BP describes no environmentally friendly chromatographic procedure since acetonitrile is one of the components of mobile phase.

This work describes a rapid and sensitive RP-HPLC method with UV detection for determination of moxifloxacin hydrochloride in bulk drug and tablet formulation with low cost of mobile phase, which was used for the first time in this work. This method serves as an alternative to the methods described in pharmacopoeias and can be conveniently used for routine quality control analysis of moxifloxacin.

\section{Experimental}

\section{Materials}

HPLC grade methanol (Merck, Germany), formic acid (AR grade, Surechem Products LTD, England) and water (HPLC grade, Merck). Moxifloxacin hydrochloride (MOXF) pure drug substance, its purity was found to be $99.7 \%$, and rosuvastatin calcium (ROSV) was obtained from Matrix Laboratories Limited and MSN Laboratories Limited (India), respectively. Tablets were purchased from Syrian market, containing moxifloxacin hydrochloride $400 \mathrm{mg}$ per tablet.

\section{Instrumentation}

A liquid chromatography (Hitachi Model L-2000, Japan)

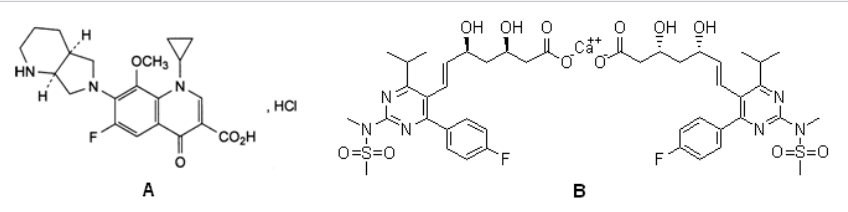

Figure 1: (A)Chemical structure of moxifloxacin $\mathrm{HCl}$

(B) Rosuvastatin calcium 
system equipped with a binary pump, degasser, column oven, auto sampler and photodiode array (PDA) detector containing a quartz flow cell (10 $\mathrm{mm}$ path and $13 \mathrm{~L}$ volume). The HPLC system was well equipped with Ezchrom Elite Hitachi software for data processing. Other instruments like Metrohm compact titrator, Sartorius analytical balance, WTW pH meter and Dihan sonicator were used in sample and standard preparations.

\section{Chromatographic conditions}

The column used was Nucleodur C18 $(250 \times 4.6 \mathrm{~mm}, 5 \mathrm{~m}$ particle size, Macherey-Nagel Germany). The mobile phase was $0.1 \mathrm{M}$ formic acid and methanol in the ratio of 30:70, filtered through nylon $0.45 \mathrm{~m}$ membrane filter and degassed by ultrasonic agitation before use. The mobile phase was prepared weekly and has a flow rate of $1.0 \mathrm{~mL} / \mathrm{min}$. The injection volume was $10 \mathrm{~L}$ with ambient column oven temperature. Isocratic elution of all analytes was monitored at $280 \mathrm{~nm}$.

\section{Standard solutions and calibration graph}

Stock solution of moxifloxacin hydrochloride containing 2.0 $\mathrm{mg} / \mathrm{mL}$ was prepared in HPLC grade methanol. Further dilutions from stock solution were made using methanol as a solvent. Stock solution of rosuvastatin calcium containing $1.0 \mathrm{mg} / \mathrm{mL}$ was prepared in methanol. Solutions were found to be stable for one month at least when stored in the dark at $2-8{ }^{\circ} \mathrm{C}$. A series of working standard solutions of MOXF equivalent to 1.12-590.0 $\mu \mathrm{g} / \mathrm{mL}$ were prepared by diluting the stock standard solution with the methanol. In each sample $6 \mathrm{~mL}$ of ROSV was added $(600$ $\mu \mathrm{g} / \mathrm{mL}$ in the final volume). To construct the calibration curve five replicates $(10 \mathrm{~L})$ of each standard solution were injected immediately after preparation into the column and the peak area of the chromatograms were measured. Then, the mean peak area ratio of MOXF to that of the internal standard was plotted against the corresponding concentration of MOXF to obtain the calibration graph.

\section{Sample preparation}

An accurately weighed quantity of powdered tablets equivalent to $200 \mathrm{mg}$ of MOXF was transferred into $100 \mathrm{~mL}$ volumetric flask and extracted with $50 \mathrm{~mL}$ methanol in an ultrasonic bath for $10 \mathrm{~min}$. The volume was completed with methanol and filtered. A suitable concentration was prepared by diluting $0.5 \mathrm{~mL}$ of the filtrate with methanol to $10 \mathrm{~mL}$ in volumetric flask containing $6 \mathrm{~mL}$ of the internal standard. The solution was then analyzed as mentioned under the construction of calibration graphs.

\section{Results and Discussion}

\section{Method development and optimization of chromatographic conditions}

Rosuvastatin calcium (Figure 1) was used as internal standard (I.S.), to improve the analytical performance and thus control undetermined changes in active pharmaceutical ingredient concentration and instrument response fluctuations, and also to reduce the problem of the many-fold dilution required in the classical batch procedures.
In this study, Nucledur C18 column gave the most suitable resolution between MOXF and ROSV peaks ( $>4$ ) according to the pharmacopeial requirement while the other columns (Nucleodur C8, Hichrom 5 C8, ODS Hypersil C18) cause the peaks of the MOXF and ROSV either to be overlapped or to have unsuitable resolution $(<4)$.

To optimize the best conditions for separation of MOXF from internal standard, the effects of methanol volume percentage (60-80\%), flow rate $(0.8-1.3 \mathrm{~mL} / \mathrm{min})$, concentration of formic acid $(0.1-0.7 \mathrm{M})$ and $\mathrm{pH}$ of the aqueous solution (2.30-2.90) were studied. Factor levels are given in parenthesis. For all experimental concentration values, the drugs are eluted in order of MOXF and ROSV.

The percentage of methanol in the mobile phase had a significant effect on the retention behavior of the studied compounds. A satisfactory separation of MOXF and ROSV with satisfactory resolution and increased speed was obtained with a mobile phase containing $70 \%$ methanol. An increase in the percentage of methanol decreases the retention of compounds; MOXF and ROSV. Increasing methanol percentage to more than $80 \%$ MOXF peak is eluted with the solvent front, while at methanol percentage lower than $60 \%$ the elution of ROSV peak is seriously delayed, as shown in Figure 2.

For further optimization, formic acid concentrations at different $\mathrm{pH}$ values (ranging from 2.30 to 2.90 ) were tried as the aqueous phase along with $70 \%$ methanol in the mobile phase. Interestingly very good separation was achieved on a C18 stationary phase with the mobile phase in which the $\mathrm{pH}$ of the aqueous phase was adjusted to 2.80 . Finally the mobile phase consisting of methanol: $0.1 \mathrm{M}$ formic acid adjusted to $\mathrm{pH} 2.80$ in a ratio of $(70: 30, v / v)$ at a flow rate of $1.0 \mathrm{~mL} / \mathrm{min}$ was found appropriate allowing adequate separation of MOXF and ROSV. Injection volume $10 \mu \mathrm{L}$ and run time $9 \mathrm{~min}$.

The use of isocratic elution was proven to be short retention time for the MOXF peak and helped in the separation of MOXF and ROSV. Figure 3 shows a typical chromatogram obtained by the proposed RP-HPLC method, demonstrating the resolution of

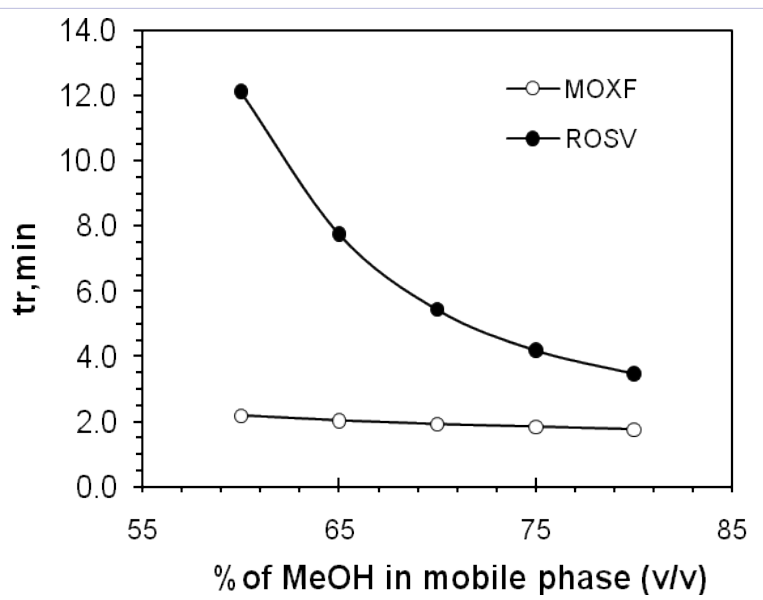

Figure 2: Plots of the retention time vs. methanol percentage in the mobile phase of MOXF and ROSV. 
the symmetrical peaks corresponding to MOXF and ROSV with a flow rate of $1.0 \mathrm{~mL} / \mathrm{min}$. The retention time of MOXF and ROSV was about 2.027 and $7.680 \mathrm{~min}$, respectively. The retention time observed allows a fast determination of the drug, which is suitable for QC laboratories. The optimum wavelength for detection was at $280 \mathrm{~nm}$, at which the best detector responses for all substances were obtained.

\section{Method validation}

The method was validated according to ICH guidelines [41]. The following validation characteristics were addressed:

\section{System suitability}

System suitability tests are an integral part of a liquid chromatographic method, and they were used to verify that the proposed method was able to produce good resolution between the peaks of interest with high reproducibility. The system suitability was determined by making seven replicate injections from freshly prepared standard solutions (containing $100 \mu \mathrm{g} /$ $\mathrm{mL}$ of MOXF in the presence of $600 \mu \mathrm{g} / \mathrm{mL}$ of internal standard) and analyzing each solute for their peak area, theoretical plates, resolution, tailing factors, capacity factor and selectivity. The system suitability requirements for MOFX and ROSV were a \% RSD of peak areas less than $0.36 \%$, peak tailing factor less than 1.02 and peak resolution greater than 4.0 between adjacent peaks for the analyte. This method met these requirements. The results of system suitability test in comparison with the required limits are shown in Table 1. According to the results presented, the proposed method fulfils these requirements within the accepted limits.

\section{Specificity}

Specificity is the ability of the method to accurately measure the analyte response in the presence of all potential sample components. The specificity of the chromatographic method was determined to ensure separation of MOXF and ROSV as illustrated in Figure 3 where complete separation of MOXF was noticed. The HPLC chromatogram recorded for the analyte in tablet (Figure 4) showed almost no peaks within a retention time range of 9 min. The figure show that MOXF is clearly separated and the peak of analyte was pure and excipients in the formulation did not interfere the analyte.

\section{Linearity and limits of detection and quantification}

The calibration curve for MOXF was constructed by ploting the ratio of the peak area of MOXF to peak area of the internal standard (ROSV) against the concentratation. The plot showed a linear range 1.12-590.0 $\mathrm{\mu g} / \mathrm{mL}$ for MOXF with correlation coefficient of the regression equation [42] greater than 0.999 in all cases and results are summarized in Table 2.

The limit of detection (LOD) and limit of quantification (LOQ) were determined experimentally. LOD was expressed as the concentration of compound that generated a response to three times of the signal to-noise $(\mathrm{S} / \mathrm{N})$ ratio, and LOQ was 10 times of the $\mathrm{S} / \mathrm{N}$ ratio [43]. The LOD and LOQ parameters were determined from regression equations of MOXF; LOD $(k=3)=k \times S_{\mathrm{a}} / b$, $\mathrm{LOQ}_{(k=10)}=k \times S_{\mathrm{a}} / b$ (where $b$ is the slope of the calibration curve and

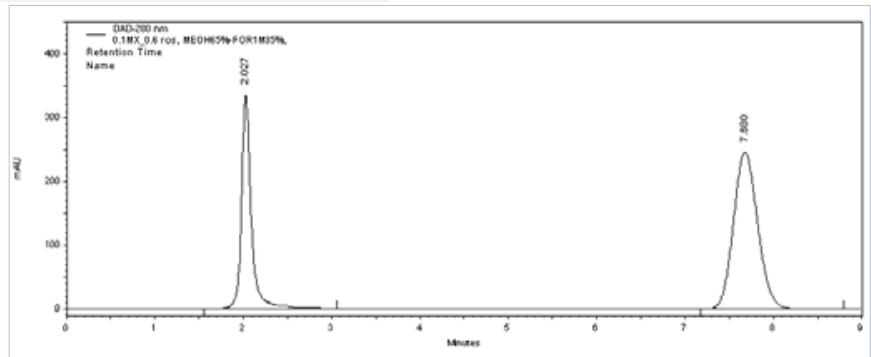

Figure 3: A typical chromatogram of a mixture of MOXF $(100 \mu \mathrm{g} / \mathrm{mL})$ and ROSV $(600 \mu \mathrm{g} / \mathrm{mL})$ under optimal conditions.

\begin{tabular}{|c|c|c|c|}
\hline Parameters & MOXF & ROSV & $\begin{array}{l}\text { Preferable } \\
\text { levels }\end{array}$ \\
\hline $\begin{array}{l}\text { Number of } \\
\text { theoretical } \\
\text { plates }(N)\end{array}$ & 5675 & 10899 & $>2500$ \\
\hline Resolution $\left(R_{s}\right)$ & - & 8.5 & $>1.5$ \\
\hline $\begin{array}{l}\text { Tailing factor } \\
(T)\end{array}$ & 0.9 & 1.02 & $<1.5$ \\
\hline $\begin{array}{l}\text { Capacity factor } \\
\left(k^{\prime}\right)\end{array}$ & 5.4 & 4.8 & $2-10$ \\
\hline Selectivity $(\alpha)$ & - & 1.12 & $1.0-2.0$ \\
\hline $\begin{array}{l}\% \text { RSD for } \\
\text { seven injections }\end{array}$ & 0.33 & 0.36 & $<5 \%$ \\
\hline
\end{tabular}

Table 2: Calibration data for the estimation of MOXF by HPLC.

\begin{tabular}{|c|c|}
\hline Parameters & MOXF \\
\hline $\begin{array}{l}\text { Optimum concentration range }(\mu \mathrm{g} / \\
\mathrm{mL})\end{array}$ & $1.12-590.0$ \\
\hline Regression equation* & $A_{\text {MоХF }}=9.687 C_{\text {мохF }}+47.927$ \\
\hline Correlation coefficient (r) & 0.9999 \\
\hline Standard deviation of slope & 0.0545 \\
\hline Standard deviation of intercept & 2.7657 \\
\hline Regression equation** & $R_{\text {MOXF } / \text { ROSV }}=0.0049 C_{\text {MOXF }}+0.0245$ \\
\hline Correlation coefficient (r) & 0.9999 \\
\hline Standard deviation of slope & 0.00005 \\
\hline Standard deviation of intercept & 0.0014 \\
\hline $\begin{array}{l}\text { Limit of quantification, } \mathrm{LOQ}(\mu \mathrm{g} / \mathrm{I} \\
\mathrm{mL})\end{array}$ & 0.78 \\
\hline Limit of detection, $\mathrm{LOD}(\mu \mathrm{g} / \mathrm{mL})$ & 0.23 \\
\hline
\end{tabular}

$S_{\mathrm{a}}$ is the standard deviation of the intercept). LOD and LOQ were 0.23 and $0.78 \mu \mathrm{g} / \mathrm{mL}$, respectively, showed good sensitivity of the proposed method.

\section{Accuracy and precision}

Intra and inter-day precision of the method were determined 
Table 3: Accuracy and precision of within and between run analysis for determination of MOXF by HPLC.

\begin{tabular}{|c|c|c|c|c|c|c|}
\hline \multirow[b]{2}{*}{ Concentration $(\mu \mathrm{g} / \mathrm{mL})$} & \multicolumn{3}{|c|}{ Intra-day $(n=5)$} & \multicolumn{3}{|c|}{ Inter-day $(n=5)$} \\
\hline & $\begin{array}{l}\text { Mean } \pm S D \\
(\mu \mathrm{g} / \mathrm{mL})\end{array}$ & $\begin{array}{l}\text { RSD } \\
\text { (\%) }\end{array}$ & $\begin{array}{l}\text { Recovery } \\
(\%)\end{array}$ & $\begin{array}{l}\text { Mean } \pm S D \\
(\mu \mathrm{g} / \mathrm{mL})\end{array}$ & RSD (\%) & Recovery (\%) \\
\hline 1.12 & $1.13 \pm 0.02$ & 1.77 & 100.89 & $1.11 \pm 0.02$ & 1.80 & 99.11 \\
\hline 20.00 & $20.77 \pm 0.23$ & 1.11 & 103.85 & $19.96 \pm 0.26$ & 1.30 & 99.80 \\
\hline 50.00 & $50.80 \pm 0.47$ & 0.92 & 101.60 & $50.06 \pm 0.50$ & 0.99 & 100.12 \\
\hline 100.00 & $101.01 \pm 0.79$ & 0.78 & 101.01 & $100.14 \pm 0.81$ & 0.81 & 100.14 \\
\hline 200.00 & $200.48 \pm 1.25$ & 0.62 & 100.24 & $200.05 \pm 1.28$ & 0.64 & 100.02 \\
\hline 400.00 & $400.64 \pm 2.22$ & 0.55 & 100.16 & $399.98 \pm 2.18$ & 0.54 & 99.99 \\
\hline 590.00 & $590.42 \pm 2.02$ & 0.34 & 100.07 & $589.97 \pm 2.25$ & 0.38 & 99.99 \\
\hline
\end{tabular}

Table 4: Results of robustness study.

\begin{tabular}{|c|c|c|c|}
\hline \multirow[b]{2}{*}{ Factor } & \multirow[b]{2}{*}{ Level } & \multicolumn{2}{|l|}{ MOXF } \\
\hline & & $\begin{array}{l}\text { \% Mean assay } \\
(n=3)\end{array}$ & $\%$ RSD of results \\
\hline \multirow{2}{*}{$\begin{array}{l}\mathrm{HCOOH} \text { in mobile phase } \\
\text { (M) }\end{array}$} & 0.08 & 99.52 & 1.54 \\
\hline & 0.12 & 101.03 & 0.74 \\
\hline \multirow{2}{*}{ Flow rate $(\mathrm{mL} / \mathrm{min})$} & 0.9 & 100.95 & 0.92 \\
\hline & 1.1 & 101.30 & 0.98 \\
\hline \multirow{2}{*}{$\%$ of methanol } & 65 & 100.68 & 1.63 \\
\hline & 75 & 102.03 & 1.07 \\
\hline
\end{tabular}

Table 5: Determination of MOXF in tablets by the proposed and pharmacopeial methods.

\begin{tabular}{|c|c|c|c|c|}
\hline \multirow[b]{2}{*}{ Formulation } & \multicolumn{2}{|c|}{$\%{\text { Recovery } \pm S D^{\text {a }}}$} & \multirow[b]{2}{*}{$t$-value ${ }^{b}$} & \multirow[b]{2}{*}{$F$-value ${ }^{b}$} \\
\hline & $\begin{array}{l}\text { Proposed } \\
\text { method }\end{array}$ & $\begin{array}{l}\text { Pharmacopeial } \\
\text { method }\end{array}$ & & \\
\hline $\begin{array}{l}\text { Moxiflox }^{\mathrm{c}} \\
\text { (400mg/ } \\
\text { tablet) }\end{array}$ & $100.26 \pm 0.33$ & $100.09 \pm 0.27 \mathrm{v}$ & 1.74 & 1.49 \\
\hline $\begin{array}{l}\text { Moxicin }^{\mathrm{d}} \\
\text { (4000mg/ } \\
\text { tablet) }\end{array}$ & $101.04 \pm 0.29$ & $99.98 \pm 0.18$ & 1.84 & 2.59 \\
\hline $\begin{array}{l}\text { Aviloxin }{ }^{\mathrm{e}} \\
\text { (400mg/ } \\
\text { tablet) }\end{array}$ & 102.000 .23 & $100.06 \pm 0.16$ & 2.03 & 2.07 \\
\hline $\begin{array}{l}\text { Adamox } \mathrm{f} \\
\text { (400mg/ } \\
\text { tablet) }\end{array}$ & $102.26 \pm 0.31$ & $101.05 \pm 0.24$ & 1.35 & 1.67 \\
\hline $\begin{array}{l}\text { Moxaquin } \\
\mathrm{g} \text { ( } 400 \mathrm{mg} / \\
\text { tablet) }\end{array}$ & 101.520 .42 & $100.62 \pm 0.39$ & 1.82 & 1.16 \\
\hline \multicolumn{5}{|c|}{$\begin{array}{l}\text { a. Five independent analyses. b. Theoretical values for } t \text { and F-test } \\
\text { at five degree of freedom and } 95 \% \text { confidence limit are } t=2.776 \text { and } \\
F=6.26 \text {. c. Supplied by Razi Labs., d. supplied by Ibn Al Haytham, e. } \\
\text { supplied by Ibn hayan, f. supplied by adamco and g. supplied by Oubari } \\
\text { Pharma, Syria. }\end{array}$} \\
\hline
\end{tabular}

by performing replicate $(n=5)$ analyses of standards and samples. Intra-day assay variation was evaluated by injecting these samples in the same day. Inter-day assay variation was evaluated by injecting these samples on 7 different days from day 1 to 30 after preparation. Recovery study was performed in view to justify accuracy of the proposed method. To determine recovery of MOXF at concentrations of 1.12, 20,50,100, 200, 400 and 590 $\mu \mathrm{g} / \mathrm{mL}$ and of ROSV at the concentration used in the assay ( 600 $\mu \mathrm{g} / \mathrm{mL}$ ) from bulk and formulations, an identical set of standards prepared in the methanol was analysed. Absolute recoveries at each concentration were measured by comparing the response of pre-treated standards with the response of standards which had not been subjected to sample pre-treatment.

Accuracy was determined by calculating the recovery. The method was found to be accurate with \% recovery $100.07 \%$ $103.85 \%$ for MOXF (Table 3 ).

Precision: a) Variation of results within the same day (intraday), variation of results between days (inter-day) was analyzed. For intra-day $(n=5) \%$ RSD was found to be $0.34-1.77 \%$ and $\%$ RSD for inter-day ( $\mathrm{n}=5)$ was $0.38-1.80 \%$. The $\%$ RSD is $<2$ which indicate that the method is precise (Table 3). b) Repeatability data are shown in Table 5. The \% RSD is $<2$ for MOXF which indicate that the method is precise.

\section{Robustness}

Robustness of HPLC method was determined by deliberately varying certain parameters like flow rate, percentage of organic solvent in mobile phase and $\mathrm{pH}$ of mobile phase. For all changes in conditions the samples were analysed in triplicate. When the effect altering one set of conditions was tested, the other conditions were held constant at optimum values.

The robustness was investigated by achieving deliberate changes in concentration of formic acid by $\pm 0.02 \mathrm{M}$, flow rate by $\pm 0.1 \mathrm{~mL} / \mathrm{min}$ and change in methanol composition of mobile phase by $\pm 5 \%$. Robustness of the method was carried out in triplicate at a concentration of $100 \mu \mathrm{g} / \mathrm{mL}$. The system suitability parameters remained unaffected over deliberate small changes in the chromatographic system, illustrating that the method was robust over an acceptable working range of its HPLC operational parameters (Table 4).

\section{Method application}

The proposed, developed and validated method was applied to determine MOXF in its marketed formulations as shown in Figure 4 and Table 5 . As can be seen from Table 5, the proposed methods have the advantages of being virtually free from interferences by excipients commonly found in tablets or from 


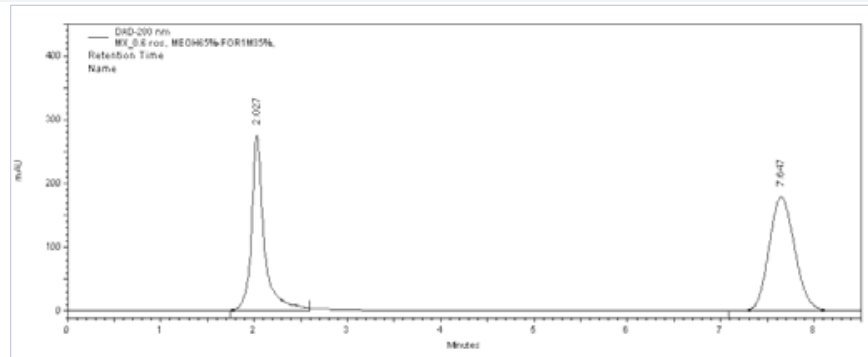

Figure 4: A typical chromatogram of a mixture of MOXF $(100 \mu \mathrm{g} / \mathrm{mL})$ and ROSV $(600 \mu \mathrm{g} / \mathrm{mL})$ in methanol, prepared from Moxicin $400 \mathrm{mg}$ tablets under the optimal conditions.

common degradation products. Student's t-test was used for statistical analysis of the data and statistical significance was defined at the level of $P<0.05$. The results obtained with the proposed method were compared statistically by the Student's $t$-test (for accuracy) and the variance ratio $F$-test (for precision) with those obtained by the official method [39] for the samples of the same batch (Table 5). Good agreement with results obtained by the official method was observed. The proposed method is simple, rapid, accurate, highly sensitive and suitable for the routine quality control.

\section{Conclusion}

The developed and validated HPLC method with UV detection for analysis of MOFX in bulk and pharmaceutical preparations is very rapid, accurate and precise. The method was successfully applied for determination of MOXF in its pharmaceutical tablet formulation with limit of quantification of $0.78 \mu \mathrm{g} / \mathrm{mL}$ and limit of detection of $0.23 \mu \mathrm{g} / \mathrm{mL}$. Moreover, the lower solvent consumption along with the short analytical run time of $9 \mathrm{~min}$ and the possibility of analysis of a large number of samples, both of which significantly reduce the analysis time per sample, leads to an environmentally friendly chromatographic procedure. Hence, this method can be conveniently used for routine quality control analysis of MOXF in its pharmaceutical formulation.

\section{References}

1. Maryadele J O'Neil. The Merck Index: An Encyclopedia of Chemicals, Drugs, and Biologicals, Royal Society of Chemistry, Cambridge. UK. $15^{\text {th }}$ ed. 2013.

2. Barman Balfour JA, Lamb HM. Moxifloxacin: a review of its clinical potential in the management of community-acquired respiratory tract infections. Drugs. 2000; 59(1):115-139.

3. Ocaña JA, Barragán FJ, Callejón M, De la Rosa F. Application of lanthanide-sensitised chemiluminescence to the determination of levofloxacin, moxifloxacin and trovafloxacin in tablets. Microchim Acta. 2004;144(1-3):207-213.

4. Abdellaziz LM, Hosny MM. Development and validation of spectrophotometric, atomic absorption and kinetic methods for determination of moxifloxacin hydrochloride. Anal Chem Insights. 2011;6:67-78.

5. AL-Ghannam SM. Atomic absorption spectroscopic, conductometric and colorimetric methods for determination of some fluoroquinolone antibacterials using ammonium reineckate. Spectrochim Acta Part A. 2008;69(4):1188-1194.
6. Motwani SK, Chopra S, Ahmad FJ, Khar RK. Validated spectrophotometric methods for the estimation of moxifloxacin in bulk and pharmaceutical formulations. Spectrochim Acta Part A. 2007;68(2):250-256.

7. Elbashir AA, Ebraheem SA, Elwagee AH, Aboul-Enein HY. New Spectrophotometric methods for the determination of moxifloxacin in pharmaceutical formulations. Acta Chim Slov. 2013;60(1):159-165.

8. Attimarad M, Al-Dhubiab BE, Alhaider IA, Nair AB, Sree Harsha N, Mueen Ahmed K. Simultaneous determination of moxifloxacin and cefixime by first and ratio first derivative ultraviolet spectrophotometry. Chem Cent J. 2012;6(105);1-7.

9. Gouda AA, Amin AS, El-Sheikh R, Yousef AG. Spectrophotometric determination of gemifloxacin mesylate, moxifloxacin hydrochloride, and enrofloxacin in pharmaceutical formulations using acid dyes. J Anal Meth Chem. 2014;1-16.

10. El Sheikh R, Amin AS, Gouda AA, Youssef AG. Utility of oxidationreduction reaction for determination of gemifloxacin mesylate and moxifloxacin $\mathrm{HCl}$ in pure form and in pharmaceutical formulations using N-bromosuccinimide. Pharm Anal Acta. 2013;4(5):1-7.

11. Sultan MA. New, simple and validated kinetics spectrophotometric method for determination of moxifloxacine in its pharmaceutical formulations. Arabian J Chem. 2009;2(2):79-85.

12. Abdel Wahed MG, El Sheikh R, Gouda AA, Abou Taleb S. Kinetic spectrophotometric determination of gemifloxacin mesylate and moxifloxacin hydrochloride in pharmaceutical preparations using 4-chloro-7-nitrobenzo-2-oxa-1,3-diazole. J Spectroscopy. 2014;1-12.

13. Ashour S, Bayram R. Development and validation of sensitive kinetic spectrophotometric method for the determination of moxifloxacin antibiotic in pure and commercial tablets. Spectrochem Acta Part A. 2015;140:216-222.

14. Erk N. Voltammetric behaviour and determination of moxifloxacin in pharmaceutical products and human plasma. Anal Bioanal Chem. 2004;378(5):1351-1356.

15. Trindade MAG, da Silva GM, Ferreira VS. Determination of moxifloxacin in tablets and human urine by square-wave adsorptive voltammetry. Microchem J. 2005;81(2):209-216.

16. Inam R, Mercan H, Yilmaz E, Uslu B. Differential pulse polarographic determination of moxifloxacin hydrochloride in pharmaceuticals and biological fluids. Anal Lett. 2007;40(1-3):529-546.

17. Ocaña JA, Barragán FJ, Callejon M. Spectrofluorimetric determination of moxifloxacin in tablets, human urine and serum. Analyst. 2000;125(12):2322-2325.

18. Ulu ST. Spectrofluorimetric determination of fluoroquinolones in pharmaceutical preparations. Spectrochim Acta Part A. 2009;72(1):138-143.

19. Kamruzzaman M, Alam A, Lee SH, Ragupathy D, Kim YH, Park SR, et al. Spectrofluorimetric study of the interaction between europium(III) and moxifloxacin in micellar solution and its analytical application. Spectrochim Acta Part A. 2012;86:375-380.

20. Cruz LA, Hall R. Enantiomeric purity assay of moxifloxacin hydrochloride by capillary electrophoresis. J Pharm Biomed Anal. 2005;38(1):8-13. DOI:10.1016/j.jpba.2004.12.004

21. Faria AF, de Souza MVN, de Almeida MV, de Oliveira MAL. Simultaneous separation of five fluoroquinolone antibiotics by capillary zone electrophoresis. Anal Chim Acta. 2006;579(2):185-192. 
22. Djurdjevic P, Ciric A, Djurdjevic A, Stankov MJ. Optimization of separation and determination of moxifloxacin and its related substances by RP-HPLC. J Pharm Biomed Anal. 2009;50(2):117-126. doi: 10.1016/j.jpba.2009.03.029.

23. Guerra FLB, Paim CS, Steppe M, Schapoval EES. Biological assay and liquid chromatographic method for analysis of moxifloxacin in tablets. J AOAC Int. 2005;88(4):1086-1092.

24. Naveen Kumar Reddy G, Rajendra Prasad VVS, Maiti NJ, Nayak D, Prashant Kumar M. Development and validation of a stability indicating UPLC method for determination of moxifloxacin hydrochloride in pharmaceutical formulations. Pharm Anal Acta. 2011;2(9):1-10. doi:10.4172/2153-2435.1000142.

25. Abdelaziz AA, Elbanna TE, Gamaleldeen NM. Validated microbiological and HPLC methods for the determination of moxifloxacin in pharmaceutical preparations and human plasma. Brazilian Journal of Microbiology. 2012;43(4):1291-1301.

26. Razzaq SN, Khan IU, Mariam I, Razzaq SS. Stability indicating HPLC method for the simultaneous determination of moxifloxacin and prednisolone in pharmaceutical formulations. Chem Cent J. 2012;6(1):1-10. DOI: 10.1186/1752-153X-6-94.

27. Motwani SK, Khar RK, Ahmad FJ, Chopra S, Kohli K, Talegaonkar S, Application of a validated stability-indicating densitometric thinlayer chromatographic method to stress degradation studies on moxifloxacin. Anal Chim Acta, 2007;582(1):75-82. DOI:10.1016/j. aca.2006.08.053.

28.Schulte S, Ackermann T, Bertram N, Sauerbruch T, Paar WD. Determination of the newer quinolones levofloxacin and moxifloxacin in plasma by high-performance liquid chromatography with fluorescence detection. J Chromatogr Sci. 2006;44(4):205-208.

29. Chan KP, Chu KO, Lai WWK, Choy KW, Wang CC, Lam DSC, et al. Determination of ofloxacin and moxifloxacin and their penetration in human aqueous and vitreous humor by using high-performance liquid chromatography fluorescence detection. Anal Biochem. 2006;353(1):30-36. DOI: 10.1016/j.ab.2006.03.016.

30. Nguyen HA, Grellet J, Boubakar BB, Quentin C, Saux MC. Simultaneous determination of levofloxacin, gatifloxacin and moxifloxacin in serum by liquid chromatography with column switching. J Chromatogr B. 2004;810(1):77-83. DOI: 10.1016/j.jchromb.2004.07.019.

31.Ocaña González JA, Callejón Mochón M, Barragán de la Rosa FJ Simultaneous determination of cefepime and the quinolones garenoxacin, moxifloxacin and levofloxacin in human urine by HPLC-
UV. Microchim Acta. 2005;151(1-2):39-45. doi:10.1007/s00604005-0391-y.

32. Laban-Djurdjević A, Jelikić-Stankov M, Djurdjević P. Optimization and validation of the direct HPLC method for the determination of moxifloxacin in plasma. J Chromatogr B. 2006;844(1):104-111. Doi: 10.1016/j.jchromb.2009.02.042.

33. Hemanth Kumar AK, Ramachandran G. Simple and rapid liquid chromatography method for determination of moxifloxacin in plasma. J Chromatogr B. 2009;877(11-12):1205-1208. DOI:10.1016/j. jchromb.2009.02.042.

34. Nemutlu E, Kir S, Ozyuncu O, Beksac MS. Simultaneous separation and determination of seven quinolones using HPLC: analysis of levofloxacin and moxifloxacin in plasma and amniotic fluid. Chromatographia. 2007;66(1):15-24. doi:10.1365/s10337-007-0292-9.

35. Vishwanathan K, Bartlett MG, Stewart JT. Determination of moxifloxacin in human plasma by liquid chromatography electrospray ionization tandem mass spectrometry. J Pharm Biomed Anal. 2002;30(4):961-968.

36. Pranger AD, Alffenaar JW, Wessels AM, Greijdanus B, Uges DR. Determination of moxifloxacin in human plasma, plasma ultrafiltrate and cerebrospinal fluid by a rapid and simple liquid chromatographytandem mass spectrometry method. J Anal Toxicol. 2010;34(3):135141.

37. Moeller JG, Stass H, Heinig R, Blaschke G. Capillary electrophoresis with laser-induced fluorescence: a routine method to determine moxifloxacin in human body fluids in very small sample volumes. J Chromatogr B. 1998;716(1-2):325-334.

38. Yang Z, Weidong Q. Separation of fluoroquinolones in acidic buffer by capillary electrophoresis with contactless conductivity detection. J Chromatogr A. 2009;1216(27):5327-5332. doi: 10.1016/j. chroma.2009.05.014.

39. British Pharmacopoeia. Vol I and II, Majestys Her' Stationery Office. London. 2013.

40.ICH. Validation of Analytical Procedure: Text and Methodology. International Conference on Harmonization. 2005.

41. Miller JC, Miller JN. Statistics in Analytical Chemistry. Ellis Horwood, Chichester, Statistics in Analytical Chemistry. $3^{\text {rd }}$ edition. London. 1993.

42. Long GL, Winefordner JD. Limit of detection A closer look at the IUPAC definition. Anal Chem. 1983;55(7):712A-721A. DOI: 10.1021/ ac00258a724. 